\title{
Granulomatosis eosinofílica con poliangitis: reporte de un caso y revisión de la literatura
}

\author{
Rubén Rodríguez-Armendáriz,® Raúl Hernández-Saldaña, Luis Carlos Hinojos-Gallardo, \\ Ernesto Ramos-Martínez, Mario Soto-Ramos
}

Hospital Infantil de Especialidades del Estado de Chihuahua, México.

Trabajo recibido: 23-VIII-2016; aceptado: 10-I-2017

\begin{abstract}
RESUMEN. La granulomatosis eosinofílica con poliangitis (GEPA), anteriormente denominado síndrome de Churg-Strauss (SCS), es un trastorno poco frecuente, de etiología desconocida, caracterizada por una vasculitis necrosante que afecta a vasos de pequeño a mediano calibre. Los pacientes presentan como rasgo característico antecedentes de asma, rinitis alérgica y eosinofilia en sangre periférica. La GEPA, antes denominado SCS es poco común en la infancia. Aunque la GEPA es una vasculitis asociada a la presencia de anticuerpos anticitoplasma de neutrófilo (ANCA), en niños sólo se encuentran en menos del $40 \%$ de los casos. La detección temprana de la enfermedad es importante ya que un retraso en el diagnóstico puede llevar a la afectación orgánica de grado variable con resultados fatales. La GEPA de inicio en la infancia representa menos del $2 \%$ de los casos de vasculitis en edad pediátrica, y sólo 50 casos de GEPA en menores de 18 años se habían publicado hasta el año 2013. Presentamos el caso de un niño de 13 años de edad con asma de difícil control y deterioro de su estado general, que finalmente fue diagnosticado con GEPA-ANCA negativo.
\end{abstract}

Palabras clave: Granulomatosis eosinofílica con poliangitis, GEPA, asma, Churg-Strauss, vasculitis.

ABSTRACT. Eosinophilic granulomatosis with poliangitis (EGPA), formerly called Churg-Strauss syndrome, is a rare disorder of unknown etiology characterized by necrotizing vasculitis that affects small vessels of medium caliber. Asthma, allergic rhinitis and peripheral blood eosinophilia are present in most patients. The EGPA in childhood is a rare clinical condition. Although EGPA is a vasculitis with neutrophil cytoplasmic antibodies related (ANCA) disorder in children, in less than $40 \%$ of all vasculitis cases are found. Early detection is important because a delay in diagnosis can lead to organ damage of varying degrees, some of them fatal. EGPA starting in childhood, represents less than $2 \%$ of cases of vasculitis in pediatric age and only 50 cases of SCS in children (<18 years old) had been published before 2013. We report the case of a 13 year old boy with difficult to control asthma and impaired general condition, which was finally diagnosed with EGPA, ANCA-negative.

Key words: Eosinophilic granulomatosis with polyangiitis, EGPA, asthma, Churg Strauss, vasculitis.

\section{INTRODUCCIÓN}

La granulomatosis eosinofílica con poliangitis (GEPA), anteriormente denominado como síndrome de ChurgStrauss, es una vasculitis necrosante sistémica que afecta a los vasos de pequeño a mediano calibre. ${ }^{1-3}$ La combinación de granulomatosis alérgica, vasculitis alérgica y periarteritis nodosa fue descrito por Churg y Strauss en 1951 como un síndrome clínico que consiste en asma severa, fiebre e hipereosinofilia, en asociación con síntomas de afectación vascular en varios órganos y sistemas. ${ }^{4-6}$

Aunque la GEPA pertenece al espectro de las vasculitis asociadas a la presencia de anticuerpos anticitoplasma de neutrófilo (ANCA), se diferencia de la granulomatosis con poliangitis y de la poliangitis microscópica debido a su asociación con asma grave y la presencia de eosinofilia periférica y tisular. ${ }^{7,8} \mathrm{La}$ presencia de ANCA en esta patología oscila entre el $30-70 \%$ de los pacientes, pero por lo general se observa con menos frecuencia en comparación con otras vasculitis asociadas a este tipo de anticuerpos. ${ }^{8,9}$ Es una enfermedad rara, su prevalencia varía entre 10.7-13 casos/millón de habitantes,,$^{10-12}$ con una incidencia anual de 0.5 a 6.8 casos nuevos/millón de habitantes. ${ }^{13-16}$ Cuando las manifestaciones clínicas incluyen asma, eosinofilia, infiltrados pulmonares, sinusitis, acompañados de hallazgos de vasculitis extrapulmonar y se cuenta con evidencia histológica de vasculitis, el diagnóstico GEPA suele ser sencillo.17,18 El hallazgo más frecuente asociado a la GEPA con ANCA positivo, es la presencia de un patrón de 
inmunofluorescencia perinuclear en la búsqueda de anticuerpos contra mieloperoxidasa (MPO). ${ }^{19-24} \mathrm{En}$ el contexto clínico de asma y eosinofilia, la presencia de estos anticuerpos sugiere altamente la GEPA; pero, por el contrario, la ausencia de los mismos no descarta el diagnóstico.

Al presente, no hay ningún biomarcador confiable para medir la actividad de la GEPA..$^{25-34}$ Una vez que se diagnostica esta vasculitis se recomienda evaluar periódicamente la función pulmonar, renal, cardíaca y gastrointestinal, así como el posible compromiso de los nervios periféricos. ${ }^{35-42}$ El compromiso renal, cardíaco y gastrointestinal se asocia con mal pronóstico y en estos casos es mandatoria la terapia inmunosupresora. ${ }^{43-47}$ Los glucocorticoides son la piedra angular del tratamiento. Los pacientes con manifestaciones sistémicas graves de la enfermedad deben recibir un régimen de inducción a remisión en combinación de glucocorticoides y otro inmunosupresor. ${ }^{47,48}$ Varias series anteriores comentan la posibilidad de que los leucotrienos (LRA) podrían haber provocado o causado GEPA. ${ }^{48,49}$ Esa atribución sigue siendo polémica y la revisión de la evidencia disponible sugiere que los LRA no causan directamente GEPA, y que la aparición de la GEPA después de comenzar los LRA podría ser una coincidencia o como resultado de una reactivación de los síntomas previamente enmascarados por el uso de esteroides. ${ }^{49}$

\section{CASO CLÍNICO}

Paciente masculino de 13 años, el cual presentaba síntomas respiratorios desde los primeros meses de edad caracterizados por tos recurrente, sin predominio de horario, exacerbada con el ejercicio, múltiples episodios de sibilancias, rinorrea hialina y congestión nasal. Al interrogatorio dirigido, no recuerdan familiares con asma, había recibido varios tratamientos en forma recurrente por sinusitis. Se documentaron antecedentes de cuatro hospitalizaciones previas por dificultad respiratoria. Acudió a consulta por presentar fiebre intermitente de tres semanas de evolución, pérdida de peso de 2 kilogramos en un mes, edema de miembros inferiores, hiperemia de la piel en ambas piernas así como nodulaciones subcutáneas en el mismo sitio, las cuales eran dolorosas a la digitopresión. Cursa con artralgias en articulaciones grandes y dolor en extremidades inferiores. El paciente había recibido tratamientos previos con expectorantes, antihistamínicos y broncodilatadores inhalados. Desde hace 3 años se aplicaba en forma diaria esteroide inhalado en combinación con broncodilatador de acción prolongada, y hace dos años fue agregado Montelukast $10 \mathrm{mg}$ diariamente.
A la exploración física se observó al paciente con mucosa nasal hiperémica, conductos auditivos permeables, membranas timpánicas integras, sin niveles hidroaéreos, cavidad oral con faringe hiperémica, tórax con amplexión y amplexación normales, región supra, inter e infraescapular sin alteraciones a la auscultación, los ruidos cardíacos rítmicos de buen tono e intensidad sin adventicios. El abdomen se encontraba plano, blando y depresible, sin hepatomegalia ni esplenomegalia, extremidades inferiores con edema, hiperemia de la piel y presencia de nodulaciones en la misma localización (figura 1). Las imágenes en la radiografía de tórax con datos de atrapamiento de aire, con líneas de engrosamiento peribronquial, rectificación del cono de la arteria pulmonar, arterias pulmonares ligeramente engrosadas, opacidad confluente hacia la proyección del segmento basal posterior del pulmón derecho sin broncograma aéreo (figura 2). La TC de tórax puso en evidencia la presencia de una imagen redondeada radiopaca con cavitación, a nivel periférico, subpleural en el segmento posterobasal derecho (figura 3, panel A, B y C). Se realizó TC de senos paranasales, la cual se reportó sin alteraciones (figura 4). Los exámenes paraclínicos se reportaron con leucocitos en 7,650, neutrófilos de 4,170 (54\%), linfocitos de 2,410 (31\%), eosinófilos de 0.597 (7.7\%), Hb $13.9 \mathrm{~g} / \mathrm{dL}$, hematocrito de $37 \%$ plaquetas de 321 mil. Creatinina en $0.69 \mathrm{mg} /$ $\mathrm{dL}$, proteínas totales $7.6 \mathrm{~g} / \mathrm{dL}$, albúmina $4.39 \mathrm{~g} / \mathrm{dL}$, globulinas $3.2 \mathrm{~g} / \mathrm{dL}$, TGO $16 \mathrm{U} / \mathrm{L}$, TGP $18 \mathrm{U} / \mathrm{L}$ DHL 166 $\mathrm{UI} / \mathrm{L}$, VSG $58 \mathrm{~mm} / \mathrm{h}$, PCR $24 \mathrm{mg} / \mathrm{dL}$.

Se realizó espirometría basal y con prueba de reto con ejercicio las cuales se encontraron normales. Se midió la fracción exhalada de óxido nítrico (FeNO),

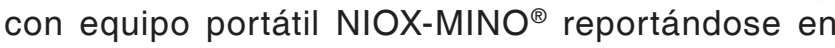

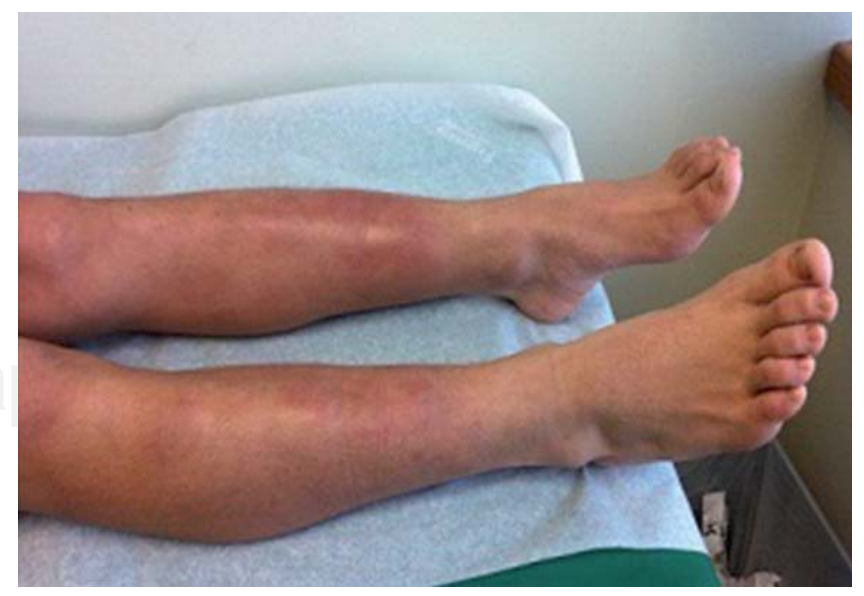

Figura 1. Imagen de miembros inferiores del paciente en la cual se observa hiperemia de la piel y nodulaciones subcutáneas. 


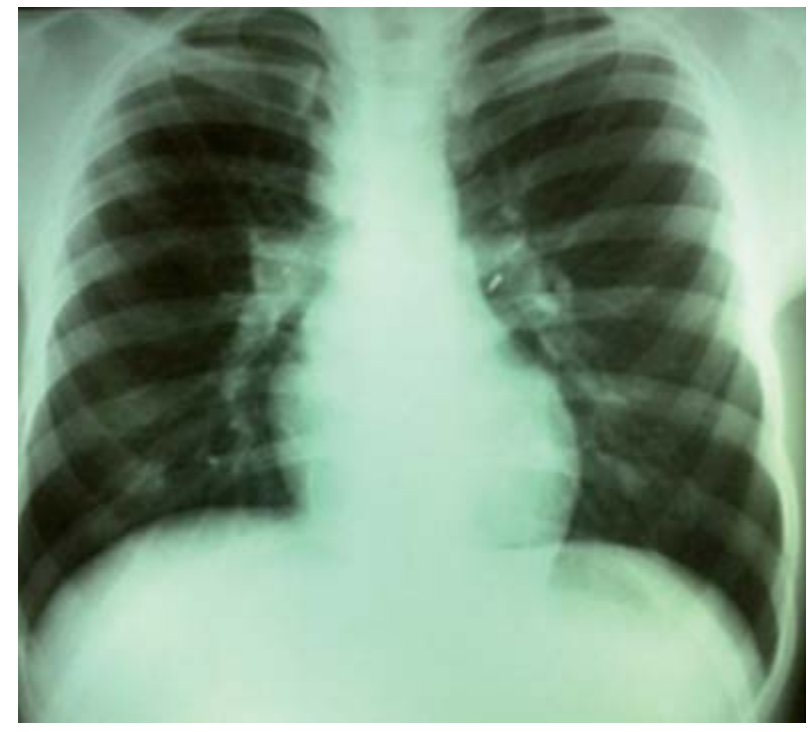

Figura 2. Radiografía de tórax la cual pone en evidencia hiperinsuflación, confluencia parahiliar, así como opacidad en proyección de lóbulo inferior derecho.
$10 \mathrm{ppb}$, haciéndose la observación de que una semana previa a la valoración se le había aplicado una dosis intramuscular de dexametasona. Se realizó electrocardiograma y ecocardiograma los cuales se reportaron normales. Se solicitaron exámenes paraclínicos en búsqueda de anticuerpos Anti DNA, anticuerpos antinucleares, c-ANCA, p-ANCA, los cuales se reportaron como negativos, la fracción $\mathrm{C} 3$ del complemento en $209.7 \mathrm{mg} / \mathrm{dL}$ (82-193), fracción C4 en $41.9 \mathrm{mg} / \mathrm{dL}(15-57 \mathrm{mg} / \mathrm{dL})$ y el complemento hemolítico (CH50) en $172.1 \mathrm{mg} / \mathrm{dL}$ (63-145 mg/dL). Examen general de orina sin proteinuria, leucocituria ni hematuria.

Se llevó a cabo biopsia de piel abarcando las áreas de hiperemia en las extremidades inferiores ya descritas, evidenciando granulomas, focos de hemorragia reciente e infiltrado focal e intersticial a expensas de histiocitos, linfocitos, eosinófilos y algunas células plasmáticas (figuras 5 y 6). Los granulomas están constituidos por células epiteloides, linfocitos, eosinófilos y algunas células gigantes multinucleadas de tipo langhans. Se hallan vasos de la microcirculación
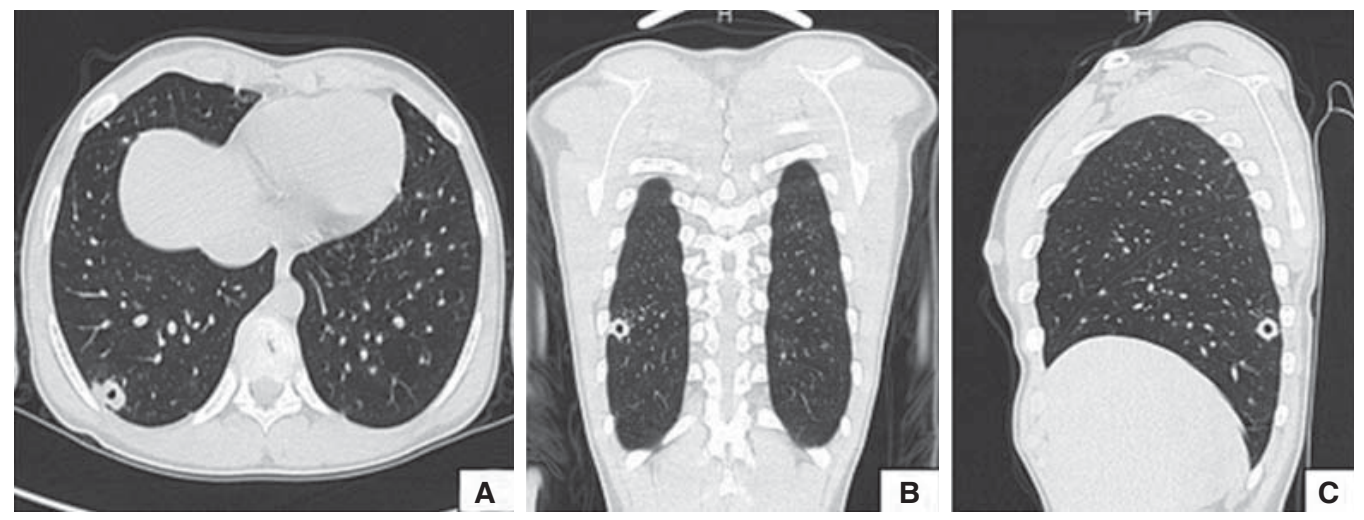

Figura 3.

Tomografía de tórax en la cual se observa imagen de cavitación a nivel subpleural en segmento 10 derecho. Panel A. Vista en proyección axial. Panel B. Vista en proyección coronal. Panel C. Vista en proyección sagital.
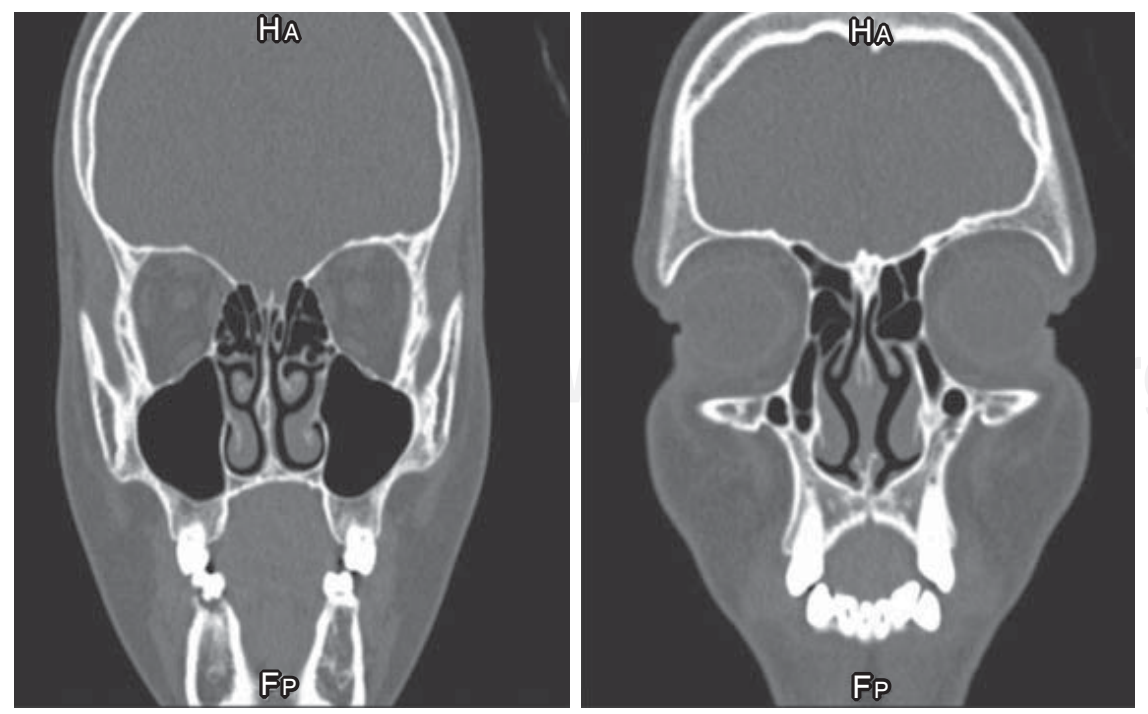

Figura 4.

Tomografía de senos paranasales sin alteraciones. 
con edema de las células endoteliales y necrosis fibrinoide de la pared con polvo nuclear e infiltrado de neutrófilos, eosinófilos e histiocitos. En el reporte histopatológico se observaron tres de los signos histológicos mayores de GEPA (vasculitis necrosante, infiltración eosinofílica y granulomas extravasculares). También desde el punto de vista clínico existen cuatro de los seis signos de la enfermedad: asma, eosinofilia, infiltración pulmonar y vasculitis histológica. Se inició tratamiento con prednisona y después se combinó con azatioprina. La evolución clínica fue hacia la mejoría. Una semana después se observó remisión de los síntomas respiratorios, así como de las lesiones en

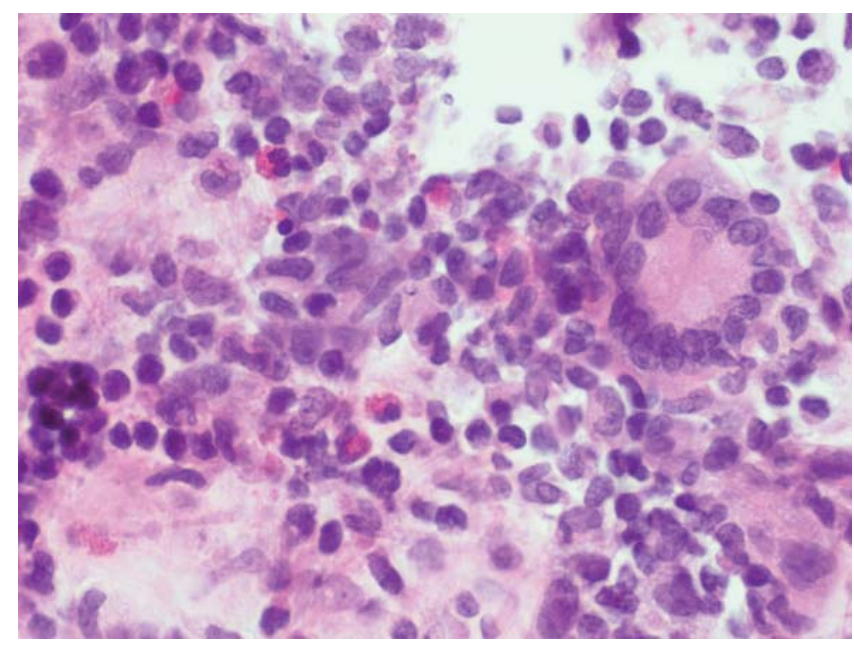

Figura 5. Biopsia de piel. En la hipodermis se aprecian eosinófilos, linfocitos e histiocitos, así como una célula gigante multinucleada de tipo Langhans. Hematoxilina-Eosina 40x.

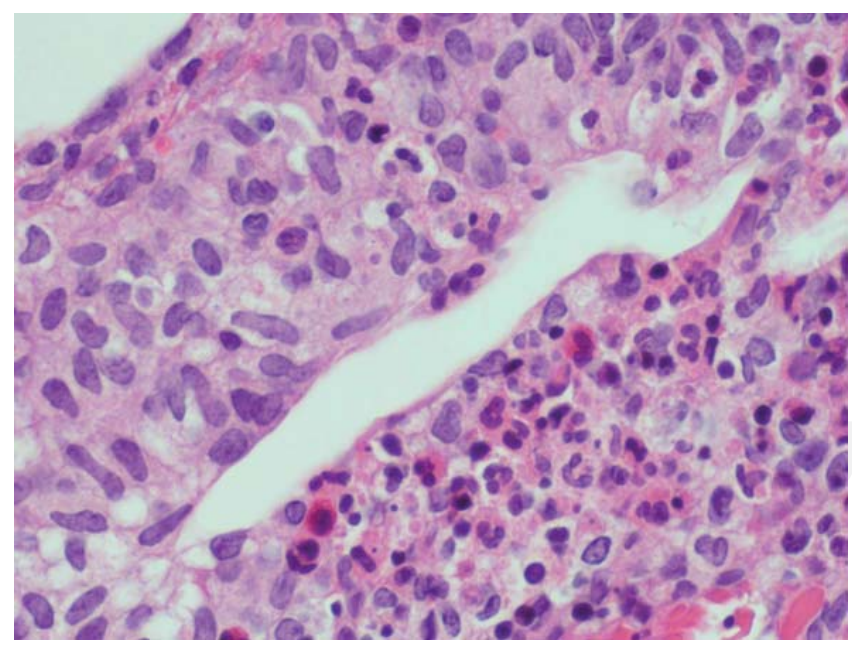

Figura 6. Biopsia de piel. Dermis con una vénula observando edema, infiltrado transmural de neutrófilos, eosinófilo, linfocitos y polvo nuclear. Hematoxilina-Eosina 400x. la piel (figura 7). A las ocho semanas se encontraba asintomático. A las 10 semanas de tratamiento se suspendió la azatioprina pues el paciente cursó con leucopenia. El paciente continúa en vigilancia tres años después del diagnóstico sin exacerbación de la enfermedad sistémica.

\section{DISCUSIÓN}

Las vasculitis pulmonares son un grupo heterogéneo de enfermedades primarias o secundarias caracterizadas por inflamación, la cual puede llevar a una destrucción progresiva de la microvasculatura pulmonar. Las características de los diferentes tipos de vasculitis dependerán de varios factores tales como el tipo de vasos afectados, el tipo de infiltrado inflamatorio y el tipo de inflamación que las rodea: necrotizante, granulomatosa con o sin depósito de complejos inmunes o anticuerpos anticitoplasma de neutrófilos. Sin embargo, el diagnóstico definitivo es a través de la biopsia, aunque la presentación clínica orienta al diagnóstico. ${ }^{1-3}$

Las vasculitis de vasos pequeños a mediano calibre afectan a niños y adultos; pero hay varias diferencias clínicas entre ambas edades que requieren ser mencionadas. ${ }^{4,5} \mathrm{En}$ primer lugar, la prevalencia de algunas formas de vasculitis depende de la edad, las vasculitis de vasos pequeños asociadas a ANCA son un hallazgo poco frecuente en niños, con una incidencia anual de 0.24 por cada 100,000 niños, siendo la granulomatosis de Wegener (GW) la vasculitis más comúnmente diagnosticada. ${ }^{6,7}$ Otro punto importante son las opciones de tratamiento, las cuales

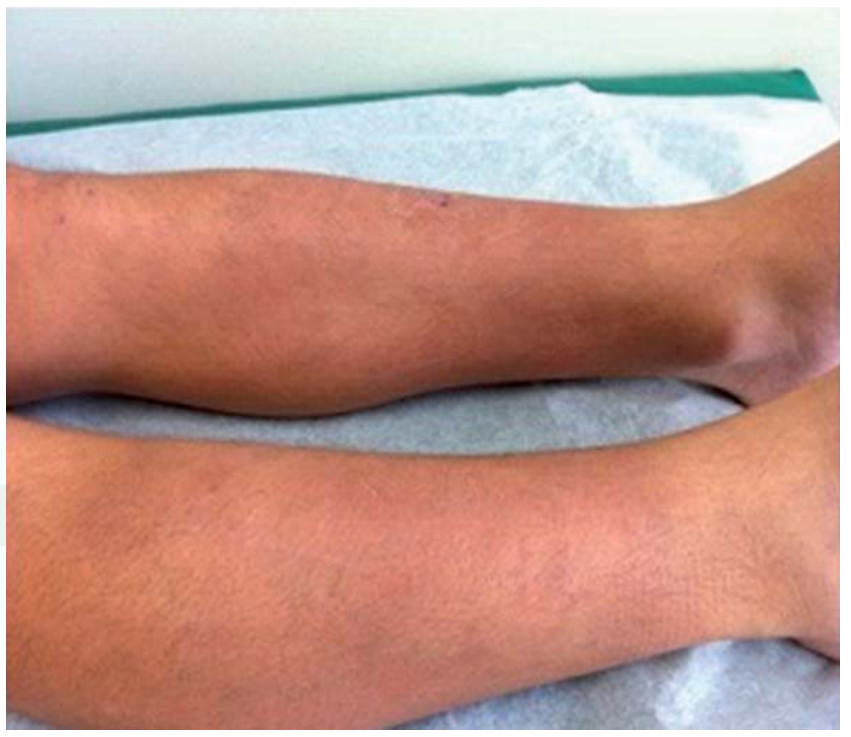

Figura 7. Imagen de miembros inferiores del paciente 8 semanas posteriores al inicio del tratamiento. 
dependerán de la edad del paciente y sus características clínicas. Las vasculitis a nivel pulmonar son una condición poco usual en el paciente pediátrico. ${ }^{8}$ Las manifestaciones sistémicas de las vasculitis incluyen malestar general, fiebre, pérdida de peso, dolor articular, lesiones cutáneas y enfermedad renal. Los pacientes que cursan con vasculitis de vasos pequeños suelen presentar manifestaciones pulmonares de la enfermedad. ${ }^{8,9}$ Un análisis de grandes bases de datos reveló que la GEPA que inicia en la infancia, sólo representa menos del $2 \%$ de todos los casos de vasculitis en edad pediátrica; y sólo 38 casos de GEPA en menores de 18 años se habían publicado hasta el año 2013, con la mayoría de los informes reportados detallando la experiencia con un solo caso. ${ }^{8,40}$

La GEPA se considera una vasculitis de vasos de pequeño y mediano calibre y por lo regular, no se hace aparente en las fases iniciales de la enfermedad.9 El órgano más afectado es el pulmón seguido de la piel; aunque puede afectar cualquier órgano incluyendo el aparato digestivo, cardiovascular, renal y el sistema nervioso central. ${ }^{9}$ Las características clínicas de GEPA es la enfermedad granulomatosa rica en eosinófilos asociada a ANCA y la cual afecta principalmente el pulmón y senos paranasales. ${ }^{9}$ La distinción de la GEPA en comparación con los otros tipos de vasculitis, es la asociación con eosinófilos en sangre periférica y asma acompañado de granulomas extravasculares y vasculitis necrosante..$^{10,11}$

El diagnóstico de la GEPA se basa en los criterios desarrollados por el Colegio Americano de Reumatología: asma, eosinofilia en sangre periférica (más del 10\% de diferencial de glóbulos blancos), mononeuropatía o polineuropatía, infiltrados pulmonares transitorios, anomalías de los senos paranasales y eosinofilia extravascular. ${ }^{11}$ Para fines de clasificación, se dice que un paciente cursa con GEPA si cuenta con al menos cuatro criterios positivos de los seis vigentes. Los criterios mencionados cuentan con una sensibilidad diagnóstica del $85 \%$ y una especificidad del $99 \%$. Los pacientes clasificados con GEPA de acuerdo con los criterios de Lanham deben contar con tres criterios: asma, recuentos de eosinófilos en sangre periférica > $1.5 \times 109 / /$ y vasculitis sistémica que implican 2 o más órganos extrapulmonares. ${ }^{12}$

La GEPA suele desarrollarse en tres fases: a) primera fase o prodrómica caracterizada por la presencia de asma y rinitis, las cuales pueden preceder al inicio de la vasculitis incluso durante varios años; b) segunda fase, la cual cursa con eosinofilia en sangre periférica y tisular; y c) tercera fase caracterizada por una vasculitis sistémica. Durante la evolución natural de la enfermedad se ha observado, incluso antes de la aparición de vasculitis $y / o$ asma, que las manifestaciones de
GEPA pueden simular otras enfermedades p. ej., asma eosinofílica, neumonía eosinofílica o síndrome hipereosinofílico, para lo cual es recomendable iniciar su estudio diagnóstico individual. ${ }^{13}$

Se ha demostrado que los ANCA se encuentran con menos frecuencia en GEPA en comparación con otras vasculitis asociadas a ANCA. El patrón principal de fluorescencia es el perinuclear con anticuerpos contra MPO; sin embargo, también se pueden encontrar anticuerpos contra PR3 en una minoría de pacientes. ${ }^{14}$

La presencia de ANCA positivos se correlaciona con afectación renal, con síntomas constitucionales y con otras manifestaciones sistémicas y de órganos específicos, como la mononeuritis, púrpura y hemorragia pulmonar. En contraste, la ausencia de ANCA se correlaciona con mayor frecuencia a manifestaciones pulmonares (con la excepción de la hemorragia alveolar) y cardíacas. ${ }^{15}$ Varios grupos han tratado de evaluar la exactitud de diferentes biomarcadores para determinar la actividad de la GEPA y de esta forma predecir las recaídas; sin embargo, los resultados no son definitivos. ${ }^{16-20} \mathrm{El}$ análisis realizado por Zwerina et al. reveló que la prevalencia de la afección de órganos individuales es diferente entre los adultos y los niños con GEPA.$^{21}$ En los niños, las neuropatías múltiples son poco frecuentes y por el contrario, en la gran mayoría de los casos pediátricos se observaron infiltrados neumónicos. El compromiso cardíaco es frecuente en niños con GEPA, ya que casi la mitad desarrolla cardiomiopatía en la serie revisada por el mencionado autor. ${ }^{22,23}$ Las manifestaciones pulmonares con infiltrados transitorios son una de las características principales de GEPA y éstos pueden anteceder a la vasculitis sistémica hasta en el $40 \%$ de los casos. Otras manifestaciones menos comunes incluyen al derrame pleural (29\%), el cual contiene un gran número de eosinófilos y el derrame pericárdico. ${ }^{23}$ Las manifestaciones extrapulmonares de la GEPA incluyen al sistema musculoesquelético (67\%), gastrointestinal (67\%), cutáneo (67\%), sistema nervioso $(56 \%)$ y sistema cardiovascular (44\%). El corazón es un órgano diana en la GEPA. ${ }^{24} \mathrm{La}$ afectación cardíaca acontece en el $48 \%$ de las muertes atribuidas a esta enfermedad, incluyendo pericarditis aguda, pericarditis constrictiva, insuficiencia cardíaca e infarto agudo al miocardio y su retraso en el tratamiento puede conducir a una falla cardíaca intratable. ${ }^{25}$

En el aparato gastrointestinal, la aparición de infiltrados submucosos de eosinófilos pueden producir masas nodulares obstructivas y la afectación de las mucosas pueden provocar diarrea y sangrado. La erupción en la piel es una de las características más comunes de la fase vasculítica de la GEPA, la cual refleja la participación de los vasos pequeños. ${ }^{26,27}$ Las 
lesiones cutáneas más frecuentes son la púrpura, la erupción eritematosa macular o papular, urticaria y nódulos subcutáneos. El compromiso renal es poco común y cuando ésta aparece, la lesión que se encuentra con mayor frecuencia es la glomerulonefritis focal y segmentaria. La naturaleza generalmente benigna de la enfermedad renal en GEPA es lo que la distingue de las otras vasculitis necrotizantes. ${ }^{28}$

En el abordaje de estudio la piel, los nervios y los músculos se encuentran entre los tejidos más frecuentemente preferidos para toma de biopsia. Los hallazgos radiológicos son variables reportándose en la literatura una incidencia del 27 a 93\% de anormalidades en las radiografías de tórax. ${ }^{29} \mathrm{El}$ hallazgo más frecuente es la consolidación multifocal periférica irregular (67\%). La tomografía de tórax evidencia diversos hallazgos anormales en el parénquima pulmonar, los cuales se pueden clasificar en tres patrones según Young Hi Choi et al. El Primer patrón es la consolidación subpleural con distribución lobar (correspondiente a un área de necrosis hemorrágica). La ubicación periférica y distribución lobar de la consolidación implica que la lesión es debido al proceso de vasculitis, la cual afecta a vasos de pequeño y mediano calibre. ${ }^{30}$ El segundo patrón es el de densidades perivasculares centrilobulillares (nódulos centrilobulillares de distribución difusa de 5 $\mathrm{mm}$ de diámetro, sobre todo dentro de la opacidad en vidrio esmerilado), aumento del calibre de las pequeñas arteriolas periféricas con opacidades perivasculares. El tercer patrón es el de nódulos múltiples y grandes. ${ }^{30-33}$

En lo referente al tratamiento los glucocorticoides son la piedra angular de las diferentes modalidades terapéuticas. ${ }^{34,35}$ En presencia de síntomas que amenazan la vida, se deberán administrar pulsos de metilprednisolona (7.5-15 mg/kg/día). Como tratamiento de inducción se sugiere iniciar prednisona a $1 \mathrm{mg} / \mathrm{kg} /$ día durante $2-3$ semanas, seguido de disminución gradual para la dosis efectiva mínima o, cuando sea posible, hasta la suspensión. ${ }^{36}$ La dosis de glucocorticoides para mantenimiento deberá ser adaptado para controlar estrechamente las necesidades de cada paciente y así evitar recaídas de manifestaciones sistémicas y controlar el asma. ${ }^{37-39}$ Los pacientes con manifestaciones sistémicas graves de la enfermedad o que pongan en riesgo la vida deben recibir un régimen de inducción a remisión en combinación de glucocorticoides y otro inmunosupresor (p. ej., ciclofosfamida). Se recomienda la terapia de mantenimiento (con azatioprina o metotrexato) para los pacientes con manifestaciones graves de la enfermedad o con afección de órganos vitales después de un régimen terapéutico de inducción a remisión. ${ }^{40,41}$ Los Intercambios de plasma generalmente no son eficaces en GEPA, pero pueden considerarse para los pacientes ANCA positivos seleccionados con glomerulonefritis rápidamente progresiva o síndrome pulmón-riñón. ${ }^{42-45}$ Recién se ha considerado al rituximab en el manejo de pacientes ANCA positivos seleccionados con afectación renal o enfermedad refractaria. ${ }^{46}$

Las tasas de remisión parecen ser más altos para ANCA positivo en comparación con los pacientes ANCA negativos. ${ }^{46,47} \mathrm{La}$ inmunoglobulina intravenosa puede considerarse un tratamiento de segunda línea para los pacientes con GEPA refractaria a otros tratamientos de glucocorticoides (y/u otros inmunosupresores) o durante el embarazo. ${ }^{46,47}$ Los antagonistas de los receptores de LRA pueden ser recetados si es necesario para los pacientes con GEPA. Varias series anteriores sugieren que el LRA podría haber provocado o causado la GEPA. ${ }^{47}$ Esa atribución sigue siendo polémica y la revisión de la evidencia disponible sugiere que los LRA no causan directamente GEPA, y que la aparición de la GEPA después de comenzar los LRA podría ser una coincidencia o como resultado de una reactivación de los síntomas previamente enmascarados por el uso de esteroides. ${ }^{48}$ La severidad del compromiso cardíaco puede explicar al menos de forma parcial, la elevada tasa de mortalidad que presenta la GEPA durante la infancia, en donde cabe destacar de que a pesar de haberse detectado la presencia de factores de mal pronóstico, la mayoría de los niños con riesgo elevado de complicaciones fueron tratados sólo con corticosteroides. Esto subraya la importancia de un tratamiento estricto y agresivo en presencia de elementos que indiquen mal pronóstico. ${ }^{49}$

\section{CONCLUSIÓN}

La presentación de este caso es de relevancia en el abordaje de estudio del asma con mal control haciendo mención a la GEPA como diagnóstico diferencial aun con anticuerpos negativos ya que, aunque su incidencia es mayor entre los pacientes asmáticos, ${ }^{15,16}$ esta patología sigue siendo poco conocida, de presentación diversa y a menudo pasa desapercibida por la mayoría de los médicos. Cabe mencionar la importancia del diagnóstico oportuno y de la detección de los factores de mal pronóstico para iniciar un tratamiento intensivo y disminuir el riesgo de complicaciones. Por ultimo, se requiere mayor evidencia para corroborar el uso de LRA en GEPA.

\section{REFERENCIAS}

1. Jennette JC, Falk RJ, Bacon PA, et al. 2012 revised International Chapel Hill Consensus Conference 
Nomenclature of Vasculitides. Arthritis Rheum 2013;65(1):1-11. doi: 10.1002/art.37715.

2. Churg J, Strauss L. Allergic granulomatosis, allergic angiitis, and periarteritis nodosa. Am J Pathol 1951;27(2):277-301.

3. Mukhtyar C, Guillevin L, Cid MC, et al.; European Vasculitis Study Group. EULAR recommendations for the management of primary small and medium vessel vasculitis. Ann Rheum Dis 2009;68(3):310-317. doi: 10.1136/ard.2008.088096.

4. Comarmond C, Pagnoux C, Khellaf M, et al.; French Vasculitis Study Group. Eosinophilic granulomatosis with polyangiitis (Churg-Strauss): clinical characteristics and long-term followup of the 383 patients enrolled in the French Vasculitis Study Group cohort. Arthritis Rheum 2013;65(1):270-281. doi: 10.1002/art.37721.

5. Sinico RA, Di Toma L, Maggiore U, et al. Prevalence and clinical significance of antineutrophil cytoplasmic antibodies in Churg-Strauss syndrome. Arthritis Rheum 2005;52(9):2926-2935.

6. Sablé-Fourtassou R, Cohen P, Mahr A, et al.; French Vasculitis Study Group. Antineutrophil cytoplasmic antibodies and the Churg-Strauss syndrome. Ann Intern Med 2005;143(9):632-638.

7. Zwerina J, Eger G, Englbrecht M, Manger B, Schett G. Churg-Strauss syndrome in childhood: a systematic literature review and clinical comparison with adult patients. Semin Arthritis Rheum 2009;39(2):108-15. doi: 10.1016/j.semarthrit.2008.05.004.

8. Healy B, Bibby S, Steele R, Weatherall M, Nelson H, Beasley R. Antineutrophil cytoplasmic autoantibodies and myeloperoxidase autoantibodies in clinical expression of Churg-Strauss syndrome. J Allergy Clin Immunol 2013;131(2):571-576.e1-6. doi: 10.1016/j. jaci.2012.05.058.

9. Keogh KA, Specks U. Churg-Strauss syndrome: clinical presentation, antineutrophil cytoplasmic antibodies, and leukotriene receptor antagonists. Am J Med 2003; 115(4):284-290.

10. Klion AD, Bochner BS, Gleich GJ, et al.; The Hypereosinophilic Syndromes Working Group. Approaches to the treatment of hypereosinophilic syndromes: a workshop summary report. J Allergy Clin Immunol 2006;117(6):1292-1302.

11. Tomac N, Yuksek M, Kunak B, Ertan U, Igde M. ChurgStrauss syndrome: a patient report in infancy. Clin Pediatr (Philadelphia) 2003;42(4):367-370.

12. Haugeberg G, Bie R, Bendvold A, Larsen AS, Johnsen V. Primary vasculitis in a Norwegian community hospital: a retrospective study. Clin Rheumatol 1998;17(5):364-368.

13. Mahr A, Guillevin L, Poissonnet M, Aymé S. Prevalences of polyarteritis nodosa, microscopic polyangiitis, Wegener's granulomatosis, and Churg-Strauss syndrome in a French urban multiethnic population in 2000: a capture-recapture estimate. Arthritis Rheum 2004;51(1):92-99.

14. Mohammad AJ, Jacobsson LT, Mahr AD, Sturfelt G, Segelmark M. Prevalence of Wegener's granulomatosis, microscopic polyangiitis, polyarteritis nodosa and
Churg-Strauss syndrome within a defined population in southern Sweden. Rheumatology (Oxford) 2007;46(8):1329-1337.

15. Watts RA, Lane S, Scott DG. What is known about the epidemiology of the vasculitides? Best Pract Res Clin Rheumatol 2005;19(2):191-207.

16. Herlyn K, Hellmich B, Gross WL, Reinhold-Keller E. Stable incidence of systemic vasculitides in Schleswig-Holstein, Germany. Dtsch Arztebl Int 2008;105(19):355-361. doi: 10.3238/arztebl.2008.0355.

17. Martin RM, Wilton LV, Mann RD. Prevalence of ChurgStrauss syndrome, vasculitis, eosinophilia and associated conditions: retrospective analysis of 58 prescriptionevent monitoring cohort studies. Pharmacoepidemiol Drug Saf 1999;8(3):179-189.

18. Harrold LR, Andrade SE, Go AS, et al. Incidence of ChurgStrauss syndrome in asthma drug users: a populationbased perspective. J Rheumatol 2005;32(6):1076-1080.

19. Moosig F, Bremer JP, Hellmich B, et al. A vasculitis centre based management strategy leads to improved outcome in eosinophilic granulomatosis and polyangiitis (Churg-Strauss, EGPA): monocentric experiences in 150 patients. Ann Rheum Dis 2013;72(6):1011-1017. doi: 10.1136/annrheumdis-2012-201531.

20. Roufosse F, Weller PF. Practical approach to the patient with hypereosinophilia. J Allergy Clin Immunol 2010;126(1):39-44. doi: 10.1016/j.jaci.2010.04.011.

21. Zwerina J, Strehl JD, Beyer C, Schett G. Can ANCA differentiate eosinophilic granulomatosis with polyangiitis (Churg-Strauss) from idiopathic hypereosinophilic syndrome? Clin Exp Rheumatol 2013;31(6):989-990.

22. Taylor MR, Keane CT, O'Connor P, Mulvihill E, Holland C. The expanded spectrum of toxocaral disease. Lancet 1988;1(8587):692-695.

23. Siddiqui AA, Berk SL. Diagnosis of Strongyloides stercoralis infection. Clin Infect Dis 2001;33(7):10401047.

24. Agarwal R. Allergic bronchopulmonary aspergillosis. Chest 2009;135(3):805-826. doi: 10.1378/chest.08-2586.

25. Cogan E, Schandené L, Crusiaux A, Cochaux P, Velu T, Goldman M. Brief report: clonal proliferation of type 2 helper $T$ cells in a man with the hypereosinophilic syndrome. N Engl J Med 1994;330(8):535-538.

26. de Lavareille A, Roufosse F, Schmid-Grendelmeier P, et al. High serum thymus and activation-regulated chemokine levels in the lymphocytic variant of the hypereosinophilic syndrome. J Allergy Clin Immunol 2002;110(3):476-479.

27. Ogbogu PU, Bochner BS, Butterfield JH, et al. Hypereosinophilic syndrome: a multicenter, retrospective analysis of clinical characteristics and response to therapy. J Allergy Clin Immunol 2009;124(6):1319-1325. e3. doi: 10.1016/j.jaci.2009.09.022.

28. Legrand F, Renneville A, Macintyre E, et al.; on behalf of the French Eosinophil Network. The spectrum of FIP1L1PDGFRA-associated chronic eosinophilic leukemia: new insights based on a survey of 44 cases. Medicine (Baltimore) 2013; 92(5): e1-e9. 
29. Marchand E, Reynaud-Gaubert M, Lauque D, Durieu J, Tonnel AB, Cordier JF. Idiopathic chronic eosinophilic pneumonia. A clinical and follow-up study of 62 cases. The Groupe d'Études et de Recherche sur les Maladies "Orphelines" Pulmonaires (GERM"O"P). Medicine (Baltimore) 1998;77(5):299-312.

30. Choi HK, Liu S, Merkel PA, Colditz GA, Niles JL. Diagnostic performance of antineutrophil cytoplasmic antibody tests for idiopathic vasculitides: metaanalysis with a focus on antimyeloperoxidase antibodies. J Rheumatol 2001;28(7):1584-1590.

31. Cordier JF, Cottin V, Guillevin L, et al. L5. Eosinophilic granulomatosis with polyangiitis (Churg-Strauss). Presse Med 2013;42(4 Pt 2):507-510. doi: 10.1016/j. Ipm.2013.02.308.

32. Groh M, Masciocco G, Kirchner E, et al. Heart transplantation in patients with eosinophilic granulomatosis with polyangiitis (Churg-Strauss syndrome). J Heart Lung Transplant 2014;33(8):842-850. doi: 10.1016/j.healun.2014.02.023

33. Samson $M$, Puéchal $X$, Devilliers $H$, et al.; French Vasculitis Study Group. Long-term outcomes of 118 patients with eosinophilic granulomatosis with polyangiitis (Churg-Strauss syndrome) enrolled in two prospective trials. J Autoimmun 2013; 43:60-69. doi: 10.1016/j.jaut.2013.03.003

34. Grayson PC, Monach PA, Pagnoux C, et al.; Vasculitis Clinical Research Consortium. Value of commonly measured laboratory tests as biomarkers of disease activity and predictors of relapse in eosinophilic granulomatosis with polyangiitis. Rheumatology (Oxford). 2015;54(8):1351-1359. doi: 10.1093/ rheumatology/keu427.

35. Guilpain P, Auclair J-F, Tamby MC, et al. Serum eosinophil cationic protein: a marker of disease activity in ChurgStrauss syndrome. Ann N Y Acad Sci 2007; 1107:392-399.

36. Hurst S, Chizzolini C, Dayer JM, Olivieri J, Roux-Lombard P. Usefulness of serum eosinophil cationic protein (ECP) in predicting relapse of Churg and Strauss vasculitis. Clin Exp Rheumatol 2000;18(6):784-785.

37. Herrmann K, Gross WL, Moosig F. Extended follow-up after stopping mepolizumab in relapsing/refractory Churg-Strauss syndrome. Clin Exp Rheumatol 2012;30(1 Suppl 70):S62-S65.

38. De Vries M, Drent M, Cohen TJ-W. Vasculitis induced by drugs. In: Camus P, Rosenow EC, editors. Drug-induced and iatrogenic respiratory disease. London: Hodder Education; 2010. p. 308-317.

39. Boyer D, Vargas SO, Slattery D, Rivera-Sanchez YM, Colin AA. Churg-Strauss syndrome in children: a clinical and pathologic review. Pediatrics 2006;118(3):e914-e920.

40. Zwerina J, Bach C, Martorana D, et al. Eotaxin-3 in Churg-Strauss syndrome: a clinical and immunogenetic study. Rheumatology (Oxford) 2011;50(10):1823-1827. doi: 10.1093/rheumatology/keq445.

41. Choi YH, Im JG, Han BK, Kim JH, Lee KY, Myoung NH. Thoracic Manifestation of Churg-Strauss syndrome: radiologic and clinical findings. Chest 2000;117(1):117124.

42. Lu S, Zhou WY, Zhou W, et al. Churg-Strauss syndrome in children: a case evolving in endomyocardiopathy. Zhongguo Dang Dai Er Ke Za Zhi 2008;10(5):625-628.

43. Guillevin L, Pagnoux C, Seror R, Mahr A, Mouthon L, Le Toumelin P.; French Vasculitis Study Group (FVSG). The Five-Factor Score revisited: assessment of prognoses of systemic necrotizing vasculitides based on the French Vasculitis Study Group (FVSG) cohort. Medicine (Baltimore) 2011;90(1):19-27. doi: 10.1097/ MD.0b013e318205a4c6.

44. Razenberg FG, Heynens JW, Jan de Vries G, et al. Clinical presentation of Churg-Strauss syndrome in children: $A$ 12-year-old-boy with ANCA-negative Churg- Strauss syndrome. Respir Med Case Rep 2012;7:4-7. doi: 10.1016/j.rmcr.2012.09.004.

45. Groh M, Pagnoux C, Baldini C, et al. Eosinophilic granulomatosis with polyangiitis (Churg-Strauss) (EGPA). Consensus Task Force recommendations for evaluation and management. Eur J Intern Med 2015;26(7):545-553. doi: 10.1016/j.ejim.2015.04.022.

46. Bouldouyre MA, Cohen P, Guillevin L. Severe bronchospasm associated with rituximab for refractory Churg-Strauss syndrome. Ann Rheum Dis 2009;68(4):606. doi: 10.1136/ard.2008.093773.

47. Pepper RJ, Fabre MA, Pavesio C, et al. Rituximab is effective in the treatment of refractory Churg-Strauss syndrome and is associated with diminished T-cell interleukin-5 production. Rheumatology (Oxford) 2008;47(7):1104-1105. doi: 10.1093/rheumatology/ ken175.

48. Gendelman S, Zeft A, Spalding SJ. Childhood-onset eosinophilic granulomatosis with polyangiitis (formerly Churg-Strauss syndrome): a contemporary single-center cohort. J Rheumatol. 2013;40(6):929-935. doi: 10.3899/ jrheum.120808.

49. Lanham JG, Elkon KB, Pusey CD, Hughes GR. Systemic vasculitis with asthma and eosinophilia: a clinical approach to the Churg-Strauss syndrome. Medicine (Baltimore) 1984;63(2):65-81.

\section{$\triangle$ Correspondencia:}

Dr. Rubén Rodríguez Armendáriz, Hospital Infantil de Especialidades del Estado de Chihuahua. México. Correo electrónico: abec_17@hotmail.com

Los autores declaran no tener conflictos de intereses. 